\title{
A Five-Day Progesterone Plus eCG-Based Fixed-Time AI Protocol Improves Fertility Over Spontaneous Estrus in High-Producing Dairy Cows Under Heat Stress
}

\author{
Irina GARCIA-ISPIERTO'), M. Angels ROSELLÓ1), Fabio DE RENSIS ${ }^{2)}$ and \\ Fernando LÓPEZ-GATIUS ${ }^{1)}$ \\ 1) Department of Animal Production, Agrotecnio, University of Lleida, Lleida, Spain \\ ${ }^{2)}$ Department of Food Science, Faculty of Veterinary Medicine, University of Parma, Parma, Italy
}

\begin{abstract}
This study compared the efficiency of a five-day or standard (nine-day) progesterone-based regimen combined with equine chorionic gonadotrophin (eCG) in a fixed-time AI (FTAI) protocol for dairy cows. The data examined were derived from 3577 inseminations conducted in three dairy herds. Animals with no estrus signs detected over 21 days were randomly assigned to a PRID-9 or PRID-5 group. Cows in each group received a progesterone intravaginal device (PRID) for 9 or 5 days, respectively, $\mathrm{PGF}_{2 \alpha}$ and eCG on PRID removal, and GnRH $48 \mathrm{~h}$ later. Fixed-time AI was performed $12 \mathrm{~h}$ after the GnRH dose. Cows artificially inseminated following spontaneous estrus during the study period were considered as controls. Based on the odds ratio, the likelihoods of animals in PRID-9 in the warm (conception rate [CR] of 22.3\%) and cool (32\% $\mathrm{CR})$ periods, and control animals in the warm period $(26.6 \% \mathrm{CR})$ becoming pregnant were reduced (by factors of $0.6,0.3$ and 0.4 , respectively) compared with the control animals in the cool period (CR of 43.7\%). The risk of a twin pregnancy was higher (51.4\%) for cystic PRID-9 cows (by a factor of 3.6) and lower (9.9\%) for cyclic PRID-5 animals (by a factor of 0.4) compared with the PRID-9 cyclic cows. These findings indicate that the proposed protocol achieves similar results during the cool or warm season to those obtained when AI is conducted at spontaneous estrus during the cool season. In addition, PRID-5 reduced twin pregnancy compared with PRID-9.
\end{abstract}

Key words: Bovine, Fertility, Hormone treatment, Pregnancy rate

(J. Reprod. Dev. 59: 544-548, 2013)

$I^{\prime}$ dairy herds worldwide, annual milk production per cow has ncreased due to improvements in management practices, genetics and nutrition. Unfortunately, in parallel with the increase in milk production, there is a rising trend in infertility and reproductive disorders $[1,2]$. The explanation for this impairment in reproductive performance is thought to be related to an observed increase in the anestrus postpartum period [3] rather than the increase in milk production [4]. In effect, over the past few years the postpartum anovulatory period at the start of the voluntary waiting period has been getting longer $[2,3,5]$.

Many estrous synchronization protocols have been tested to reduce management tasks and increase economic income. In high-producing dairy herds, these protocols should be efficient in all cows, including anestrous animals, allow for fixed-time AI (FTAI) and reduce the number of days open (short synchronization protocols).

Intravaginal progesterone-based protocols seem to be effective both in cyclic animals and in cows with cystic ovarian follicles (COF) or anovulatory follicles [6-10]. However, oocyte quality related to the use of 12-d progesterone-based protocols has been found to be poor [11], and several modifications to these protocols

Received: April 22, 2013

Accepted: July 15, 2013

Published online in J-STAGE: August 12, 2013

(C)2013 by the Society for Reproduction and Development

Correspondence: F López-Gatius (e-mail: flopez@prodan.udl.cat) exist, including reduction of the number of days of progesterone treatment and the introduction on different days of gonadotrophin releasing hormone $(\mathrm{GnRH})$, equine chorionic gonadotrophin (eCG) and prostaglandin $\mathrm{F}_{2 \alpha}[10,12]$. Short progesterone-based protocols (5 days) for fixed-time AI showed acceptable results [13]. Recently, eCG proved effective at the end of a $9 \mathrm{~d}$-progesterone treatment in long-standing non-cycling cows [14], but it seemed not to increase reproductive performance in cyclic animals. We hypothesized that a short progesterone-based protocol of five days plus eCG should be as efficient as the standard one of nine days plus eCG. Therefore, the present study was designed to compare the efficiency of a short (five-day) and standard (nine-day) progesterone-based regimen combined with eCG and GnRH in a fixed-time AI (FTAI) protocol during the cool and warm seasons in terms of their effects on the conception rate in high-producing dairy cows. Cows inseminated at spontaneous estrus during the study period were considered the control group. Due to the fact that eCG treatment can increase the risk of twin pregnancy [15], a second objective of the present study was to evaluate the effect of the proposed protocols on the twin pregnancy rate. Factors such as herd, parity and reproductive status were also included in the analyses.

\section{Material and Methods}

Cattle and herd management

The data for this study were obtained from a reproductive control 
program conducted by the University of Lleida on three well-managed, high-producing Holstein-Friesian dairy herds in northeastern Spain. The data were derived from 3577 inseminations performed over the period January 2011 to May 2012. Briefly, management was the same in the three herds and included the following common features: the use of pedometers, housing in free stalls with concrete slatted floors and cubicles, the use of fans and water sprinklers in the warm season, rigorous postpartum checks, the same reproductive health program and most AIs (over 90\%) conducted by veterinarians.

The mean annual culling rate was $30 \%$. Mean annual milk production for the herds over the study period was $10,590 \mathrm{~kg}$. The cows were grouped according to age (primiparous versus multiparous), milked three times daily and fed complete rations. Feeds consisted of cotton seed hulls, barley, corn, soybean, and bran, along with roughage, primarily corn, barley or alfalfa silage and alfalfa hay. Rations were in line with National Research Council recommendations [16]. The voluntary waiting period was 70 days.

In the geographical area of the study, there are only two clearly differentiated weather periods: the warm (May to September) and cool (October to April) periods [17]. During the study period, the mean number of days per month that the maximum temperature was higher than $25 \mathrm{C}$ ranged from 24 to 31 days and from 0 to 6 days, for the warm and cool periods, respectively. Reproductive variables are generally significantly impaired during the warm period $[2,17,18]$.

\section{Experimental design}

Only cows that did not have any disease until randomization, and cows inseminated in estrus that had no disease until bred and a body condition score between 2.5 and 3.5 were included in the study. In the final study population, there were 3577 AIs in 1056 cows, so some cows were inseminated several times and included in different groups. Control cows were all cows that were artificially inseminated (AI) following spontaneous estrus $(\mathrm{n}=2045 \mathrm{AI})$ during the study period. Cows with no estrus signs detected over 21 days entered a weekly reproductive program and were randomly assigned to a PRID-9 $(\mathrm{n}=812)$ or PRID-5 $(\mathrm{n}=720)$ group. Due to management policy, a ratio of 2/1 (PRID-9/PRID-5) was established in Herd 3 during the warm season. Cows in PRID-9 were fitted with a progesterone releasing intravaginal device (PRID, containing $1.55 \mathrm{~g}$ of progesterone; CEVA Salud Animal, Barcelona, Spain). The PRID was left for $9 \mathrm{~d}$, and these animals were also given prostaglandin $\mathrm{F}_{2 \alpha}$ (25 mg Dinoprost i.m.; Enzaprost, CEVA Santé Animale, Libourne, France), and eCG (500 IU i.m.; Syncostim, CEVA Santé Animale) upon PRID removal [14]. Forty-eight hours later, cows received GnRH (100 $\mu \mathrm{g}$ i.m.; Cystoreline, CEVA Santé Animale) and fixed-time AI (FTAI) was performed using semen of proven fertility $12 \mathrm{~h}$ after the GnRH dose. Cows in the PRID-5 group were treated similarly with the only difference being that the progesterone device was left in place for 5 days instead of 9 days. Ovarian structures were assessed on the day of treatment by ultrasonography (anovulatory follicle, cystic ovarian follicle or corpus luteum). We used the information from the reproductive check the week before treatment to diagnose anovulatory follicles at the time of treatment, and cows were considered to suffer follicular anovulation when a follicular structure of at least $8-15 \mathrm{~mm}$ was detected in two consecutive examinations seven days apart in the absence of a corpus luteum or cystic ovarian follicle, and no oestrus signs were noted during the 7-day period between the exams [9]. A cystic ovarian follicle was diagnosed when a follicular structure larger than $20 \mathrm{~mm}$ in diameter (external diameter including the wall) was detected in either or both ovaries in the absence of a corpus luteum and uterine tone [19]. Since persistency is a characteristic of ovarian cysts $[19,20]$, cystic ovarian follicles were manually ruptured at diagnosis just before treatment $[9,21]$.

\section{Insemination and pregnancy diagnosis}

Only cows showing estrus signs were inseminated (control animals). Estrus was detected using a pedometer system (AfiFarm System; SAE Afikim). Walking activity values were recorded at the milking parlor (three times daily) and analyzed automatically using a herd management computer program. A walking activity greater than $80 \%$ of the mean activity recorded in the preceding $2 \mathrm{~d}$ was taken as the lower limit for a cow to be considered in estrus. Since these herds have been noted to show a very significant relation between increased walking activity and fertility provided walking activity is increased by $80 \%$ to $993 \%$ [22], values lower than $80 \%$ were not considered as estrus signs. Also, individual information concerning prior estrus detection was taken into account. For example, if a cow showed a $120 \%$ increase in activity but showed an increase of around $400 \%$ in its last two estrus periods, the cow was explored for possible reasons other than estrus such as acute lameness or change of location. Cows that exhibited estrus within a 12-d interval were also not considered and were recorded as cows with possible reproductive disorders for inclusion in the next weekly gynecological exam program. Cows considered to be in estrus based on increasing walking activity were finally inseminated after estrus was confirmed by examination of the genital tract and vaginal fluid $[23,24]$. A cow was considered ready for service when a corpus luteum was manually or ultrasonographically estimated to be either less than 10 $\mathrm{mm}$ or nondetectable, the largest follicle showed some fluctuation upon slight pressure and had an estimated diameter of 12 to 25 $\mathrm{mm}$, the uterus was highly turgid and contractile to the touch and vaginal discharges were copious, fluid, and transparent $[25,26]$. If cows returned to estrus, their status was confirmed by examination per rectum, and the animals were recorded as nonpregnant. In the remaining cows, pregnancy diagnosis was performed by ultrasound 28-34 d post-insemination. Cows diagnosed as not pregnant were returned to the weekly reproductive program. Pregnancy was confirmed by ultrasonography at $60-66 \mathrm{~d}$ post-insemination.

\section{Data collection and analysis}

The following data were recorded for each animal: herd, parity (primiparous versus multiparous), ovarian structures upon treatment determined by ultrasonography (anovulatory follicle, cyst or corpus luteum), treatment (Control, PRID-9, PRID-5), season of insemination (cool-October to April-versus warm-May to September), milk production (mean production in the three days before treatment) and days in milk upon treatment, previous AI number, AI date, semen providing bull, AI technician, pregnancy diagnosis (PD) 28-34 d subsequent to treatment and twin pregnancy (single versus twin/ multiple).

Two binary logistic regression models were constructed for all inseminations. The dependent variables considered in these two 
models, respectively, were PD and twin pregnancy, and the independent variables were the factors cited above. In treated animals, one single further binary logistic regression analysis was performed with twin pregnancy as the dependent variable, but included ovarian structures upon treatment. Insemination was the experimental unit of the analyses, and the variable cow was treated as a repeated measure.

Regression analysis was conducted according to the method of Hosmer and Lemeshow [27] using the logistic procedure implemented in the SPSS Statistics for Windows Version 18.0 (SPSS, Chicago, IL, USA). Basically, this method involves five steps as follows: (i) preliminary screening of all variables for univariate associations, (ii) construction of a full model using all the variables found to be significant in the univariate analysis, (iii) stepwise removal of nonsignificant variables from the full model and comparison of the reduced model with the previous model for model fit and confounding, (iv) detection of plausible two-way interactions among variables and (v) assessment of model fit using Hosmer-Lemeshow statistics. Variables with univariate associations showing a $\mathrm{P}<0.25$ were included in the initial model. We continued modeling until all the main effects or interaction terms were significant according to the Wald statistic at $\mathrm{P}<0.05$. Significance was set at $\mathrm{P}<0.05$.

\section{Results}

Mean values for milk production, lactation number and previous insemination number for the study period were $45.6 \pm 5 \mathrm{~kg}, 2.4 \pm$ 1.4 and $2.9 \pm 2$, respectively (mean $\pm \mathrm{SD}$ ). The mean days in milk for control and treated cows at AI were $150 \pm 128$ and $158 \pm 150$ days, respectively. The mean conception rate was 37.6 , with a twin pregnancy rate of $18.2 \%$ for the study period $(17.5 \%$ and $19.2 \%$ for control and treated cows, respectively).

\section{All animals}

Based on the odds ratio, the likelihood of pregnancy was higher in herd 3 (1.3-fold) compared with the remaining herds and lower in multiparous cows ( 0.7 -fold) compared with primiparous animals. The interaction of treatment by season of AI was also found to be significant. This meant that animals in PRID-9 in both seasons, and control animals in the warm season were less likely to become pregnant compared with control cows inseminated during the cool season (by factors of $0.6,0.3$ and 0.4 , respectively) (Table 1). No further significant interactions were found.

No significant effects were found of any of the variables examined on the twin pregnancy rate in cows diagnosed pregnant.

\section{Treated animals}

Based on the odds ratio, the risk of twin pregnancy was higher in cystic cows in PRID-9 (by a factor of 3.6) and lower in cyclic animals in PRID-5 (by a factor of 0.4) compared with the PRID-9 cyclic animals (Table 2).

Table 1. Odds ratios and variables included in the final logistic regression model for conception in response to first insemination after treatment

\begin{tabular}{lcccccc}
\hline \multicolumn{1}{c}{ Factor } & \multicolumn{1}{c}{ Class } & $\mathrm{n}$ & $\begin{array}{c}\text { Conception } \\
\text { rate } \%\end{array}$ & Odds ratio & $\begin{array}{c}95 \% \text { Confidence } \\
\text { interval }\end{array}$ & $\mathrm{P}$ \\
\hline Herd & 1 & $490 / 1370$ & 35.8 & Reference & & \\
& 2 & $133 / 359$ & 37.0 & 0.9 & $0.7-1.2$ & 0.3 \\
& 3 & $721 / 1848$ & 39.0 & 1.3 & $1.1-1.6$ & $<0.001$ \\
Treatment $\times$ season & Control $\times$ cool & $715 / 1635$ & 43.7 & Reference & & \\
interaction & Control $\times$ warm & $109 / 410$ & 26.6 & 0.4 & $0.3-0.5$ & $<0.001$ \\
& PRID-9 $\times$ cool & $161 / 503$ & 32.0 & 0.6 & $0.5-0.7$ & $<0.001$ \\
& PRID-9 $\times$ warm & $69 / 309$ & 22.3 & 0.3 & $0.2-0.4$ & $<0.001$ \\
& PRID-5 $\times$ cool & $238 / 600$ & 39.7 & 0.9 & $0.8-1.1$ & 0.09 \\
Parity & PRID-5 $\times$ warm & $52 / 120$ & 43.3 & 1.2 & $0.6-2.6$ & 0.5 \\
& Primiparous & $455 / 1081$ & 42.1 & Reference & & \\
\hline
\end{tabular}

$\mathrm{R}^{2}$ Nagelkerke $=0.15$.

Table 2. Odds ratios and variables included in the final logistic regression model for twin pregnancy in response to first insemination after treatment (only treated animals included)

\begin{tabular}{lllcccc}
\hline \multirow{2}{*}{ Factor } & \multicolumn{1}{c}{ Class } & $\mathrm{n}$ & $\begin{array}{c}\text { Twinning } \\
\text { rate } \%\end{array}$ & Odds ratio & $\begin{array}{c}95 \% \text { Confidence } \\
\text { interval }\end{array}$ \\
\hline Treatment $\times$ ovary & PRID-9 $\times$ cyclic & $25 / 115$ & 21.7 & Reference & & P \\
structure interaction & PRID-9 $\times$ follicle* & $10 / 79$ & 12.7 & 0.5 & $0.3-1.1$ & 0.7 \\
& PRID-9 $\times$ COF** & $18 / 35$ & 51.4 & 3.6 & $0.7-8.5$ & $0.3-0.9$ \\
& PRID-5 $\times$ cyclic & $18 / 181$ & 9.9 & 0.4 & $0.4-1.9$ & 0.5 \\
& PRID-5 $\times$ follicle* & $19 / 115$ & 16.5 & 1.4 & $0.5-3.2$ & 0.5 \\
\hline
\end{tabular}

$\mathrm{R}^{2}$ Nagelkerke $=0.12 . *$ Follicle: anovulatory follicle. ${ }^{*} * \mathrm{COF}$ : cystic ovarian follicle. 


\section{Discussion}

To the best of our knowledge, no synchronization protocol for timed AI has yet proven effective in improving fertility over that observed after spontaneous estrus, especially during periods of heat stress. The protocol proposed here, a 5-day progesterone plus eCG -based regimen, achieves similar results during the cool or warm season to those obtained when $\mathrm{AI}$ is conducted at spontaneous estrus during the cool season. Moreover, this protocol reduced the twinning rate in cyclic animals compared with the 9-day regimen (PRID-9).

The impact of heat stress on the reproductive performance of dairy cows has been extensively reviewed [2, 28, 29]. Due to global warming [30], this problem is no longer restricted to tropical regions and is set to have a much greater impact on the worldwide farm economy. Strategies to combat it, such as use of fans and sprinklers, are in widespread use on well-managed high-producing dairy farms, but the effects of heat stress are still felt during autumn [31]. The results presented here raise the question of why a 5-day progesterone-based protocol rather than a 9-day progesterone-based protocol was useful during warm/hot months to obtain a conception rate similar to that in spontaneously bred cows during cool months. This improvement in fertility due to the 5-day progesterone-based protocol has two possible explanations. Firstly, high temperatures have been related to oocyte aging [32]. It seems reasonable to think that regardless of whether the lifespan of a follicular wave is shortened in short protocols, oocyte quality has less time to be affected by heat stress. Secondly, heat stress impairs dramatically ovarian function $[2,28]$. The negative effect of heat stress on endogenous progesterone has been extensively reported [28]. Although the warm season decreases circulating levels of this hormone, it is logical to think that intravaginal progesterone devices will enhance reproductive performance of dairy cows. The next question is why a 5-day progesterone-based protocol is better than a 9-day progesterone-based protocol?

It is well-established that following progesterone administration, acyclic animals increase the release of luteinizing hormone (LH) from the anterior pituitary, with the consequence of development of a follicular wave and increasing peripheral concentrations of oestradiol [33]. However, although progesterone treatment induces estrus in a herd, it reduces fertility in response to synchronized estrus [34, 35]. In addition, long conventional treatments $(>12$ days) enhance the estrous response but decrease pregnancy rates [36-39]. Hence, this could mean that fertility is not compromised when the duration of ovulatory follicle dominance is limited to 4 days [40]. The reduced fertility observed for long protocols is not attributable to lack of ovulation or subsequent luteal function. In progesterone-treated animals, the dominant follicle grows to a larger preovulatory size than normal follicles $(12.8,17.3$ and $20.8 \mathrm{~mm}$ in diameter for control cows and cows treated for 6 days or 9 days with progesterone implants, respectively) [40], and higher plasma estradiol concentrations are produced [41]. This extended growth phase leads to a higher proportion of persistent follicles entering the plateau/regression stage. The persistence of a dominant follicle could predispose it to becoming cystic [42]. Thus, it is likely that these undesirable effects are avoided in a 5-day protocol better than in a 9-day protocol. This rationale may also explain why our 9-day protocol led to a higher twinning rate in cows with cystic ovarian disease.
Multiple pregnancies are undesirable in dairy herds because there is a greater risk of pregnancy loss $[43,44]$, peripartum diseases and culling [45-47]. Synchronization protocols have been recently linked to twin pregnancies in dairy cattle [15]. In the latter study, more twin pregnancies were recorded in cows fitted with a 9-day progesterone-releasing intravaginal device and given eCG 28 days before the AI that resulted in pregnancy and in cows with a COF diagnosed in the 14 days prior to AI receiving prostaglandin treatment than in cows subjected to a 5-day progesterone protocol even if these cows had a COF. These results partly agree with those of a recent study [48] in which the treatment with prostaglandin $\mathrm{PGF}_{2 \alpha}$ plus eCG and GnRH $48 \mathrm{~h}$ later followed by FTAI in dairy cows with silent ovulation (cows with a mature corpus luteum and no signs of estrus detected in the preceding 21 days) reduced the twin pregnancy rate in multiparous cows. Follicular dynamics in short protocols needs to be better understood if we are to reduce the twinning rate in high-producing dairy herds.

In conclusion, fixed-time AI after a 5-day progesterone-based synchronized ovulation protocol combined with eCG resulted in similar fertility in high-producing dairy cows during the cool or warm season when compared to animals inseminated at spontaneous estrus during the cool season. Moreover, when used in cyclic animals, the protocol proposed reduced the twinning rate compared with a similar 9-day protocol.

\section{Acknowledgments}

The authors thank Ana Burton for assistance with the English translation. This study was partly funded by the University of Lleida (CTT C-06073 with CEVA Santé Animale, France).

\section{References}

1. Lucy MC. Reproductive loss in high-producing dairy cattle: where will it end? J Dairy Sci 2001; 84: 1277-1293. [Medline]

2. López-Gatius F. Is fertility declining in dairy cattle? A retrospective study in northeastern Spain. Theriogenology 2003; 60: 89-99. [Medline]

3. Yániz J, López-Gatius F, Bech-Sàbat G, García-Ispierto I, Serrano B, Santolaria P. Relationships between milk production, ovarian function and fertility in high-producing dairy herds in north-eastern Spain. Reprod Domest Anim 2008; 43(Suppl 4): 38-43. [Medline]

4. García-Ispierto I, López-Gatius F, Santolaria P, Yániz JL, Nogareda C, López-Béjar M. Factors affecting the fertility of high producing dairy herds in northeastern Spain. Theriogenology 2007; 67: 632-638. [Medline]

5. Opsomer G, Gröhn YT, Hertl J, Coryn M, Deluyker H, de Kruif A. Risk factors for postpartum ovarian dysfunction in high producing dairy cows in Belgium: a field study. Theriogenology 2000; 53: 841-857. [Medline]

6. Nebel RL, Jobst JM. Evaluation of systematic breeding programs for lactating dairy cows: a review. J Dairy Sci 1998; 81: 1169-1174. [Medline]

7. López-Gatius F, Santolaria P, Yániz J, Rutllant J, López-Béjar M. Persistent ovarian follicles in dairy cows: a therapeutic approach. Theriogenology 2001; 56: 649-659. [Medline]

8. López-Gatius F, Murugavel K, Santolaria P, López-Béjar M, Yániz JL. Pregnancy rate after timed artificial insemination in early post-partum dairy cows after Ovsynch or specific synchronization protocols. J Vet Med A 2004; 51: 33-38. [Medline]

9. López-Gatius F, Mirzaei A, Santolaria P, Bech-Sàbat G, Nogareda C, García-Ispierto I, Hanzen C, Yániz JL. Factors affecting the response to the specific treatment of several forms of clinical anestrus in high producing dairy cows. Theriogenology 2008; 69 : 1095-1103. [Medline]

10. Garcia-Ispierto I, López-Gatius F, Bech-Sàbat G, Yániz JL, Angulo E, Maris C, Floc'h S, Martino A. Effects of a progesterone-based oestrous synchronization protoco in 51- to 57-day postpartum high-producing dairy cows. Reprod Domest Anim 2010; 45 
e168-e173. [Medline]

11. Noble KM, Tebble JE, Harvey D, Dobson H. Ultrasonography and hormone profiles of persistent ovarian follicles (cysts) induced with low doses of progesterone in cattle. $J$ Reprod Fertil 2000; 120: 361-366. [Medline]

12. Ambrose DJ, Emmanuel DG, Colazo MG, Kastelic JP. Pregnancy rates to timed artificial insemination in Holstein heifers given prostaglandin F2alpha twenty-four hours before or concurrent with removal of an intravaginal progesterone-releasing insert. $J$ Dairy Sci 2008; 91: 2678-2683. [Medline]

13. Ribeiro ES, Monteiro APA, Lima FS, Ayres H, Bisinotto RS, Favoreto M, Greco LF, Marsola RS, Thatcher WW, Santos JEP. Effects of presynchronization and length of proestrus on fertility of grazing dairy cows subjected to a 5-day timed artificial insemination protocol. J Dairy Sci 2012; 95: 2513-2522. [Medline]

14. Garcia-Ispierto I, López-Helguera I, Martino A, López-Gatius F. Reproductive performance of anoestrus high-producing dairy cows improved by adding equine chorionic gonadotrophin to a progesterone-based oestrus synchronizing protocol. Reprod Dom Anim 2012; 47: 752-758.

15. Andreu-Vázquez C, Garcia-Ispierto I, López-Gatius F. Photoperiod length and the estrus synchronization protocol used before $\mathrm{AI}$ affect the twin pregnancy rate in dairy cattle. Theriogenology 2012; 78: 1209-1216. [Medline]

16. National Research Council. Nutrient requirements of dairy cattle, 7 th rev. ed. Washington, DC: National Academic Science; 2001

17. Labernia J, López-Gatius F, Santolaria P, Hanzen C, Laurent Y, Houtain JY. Influence of calving season on the interactions among reproductive disorders of dairy cows. Anim Sci 1998; 67: 387-393.

18. García-Ispierto I, López-Gatius F, Bech-Sabat G, Santolaria P, Yániz JL, Nogareda C, De Rensis F, López-Béjar M. Climate factors affecting conception rate of high producing dairy cows in northeastern Spain. Theriogenology 2007; 67: 1379-1385. [Medline]

19. Hanzen CH, Bascon F, Theron L, López-Gatius F. Ovarian cysts in cattle. Part 1: Definitions, symptoms and diagnostic. Ann Méd Vet 2007; 151: 247-256.

20. López-Gatius F, Santolaria P, Yániz J, Fenech M, López-Béjar M. Risk factors for postpartum ovarian cysts and their spontaneous recovery or persistence in lactating dairy cows. Theriogenology 2002; 58: 1623-1632. [Medline]

21. Hanzen C, Bascon F, Theron L, López-Gatius F. Ovarian cysts in cattle. Part 3: Therapeutic aspects. Ann Méd Vét 2008; 152: 103-115.

22. López-Gatius F, Santolaria P, Mundet I, Yániz JL. Walking activity at estrus and subsequent fertility in dairy cows. Theriogenology 2005; 63: 1419-1429. [Medline]

23. López-Gatius F, Camón-Urgel J. Increase in pregnancy rate in dairy cattle after preovulatory follicle palpation and deep cornual insemination. Theriogenology 1988; 29: 1099-1103. [Medline]

24. López-Gatius F. Site of semen deposition in cattle: a review. Theriogenology 2000; 53: 1407-1414. [Medline]

25. Roelofs J, López-Gatius F, Hunter RHF, van Eerdenburg FJCM, Hanzen CH. When is a cow in estrus? Clinical and practical aspects. Theriogenology 2010; 74: 327-344. [Medline]

26. López-Gatius F. Feeling the ovaries prior to insemination. Clinical implications for improving the fertility of the dairy cow. Theriogenology 2011; 76: 177-183. [Medline]

27. Hosmer DW, Lemeshow S. Applied Logistic Regression. New York: Wiley; 1989

28. De Rensis F, Scaramuzzi RJ. Heat stress and seasonal effects on reproduction in the dairy cow-a review. Theriogenology 2003; 60: 1139-1151. [Medline]

29. López-Gatius F. Factors of a noninfectious nature affecting fertility after artificial insemination in lactating dairy cows. A review. Theriogenology 2012; 77: 1029-1041. [Medline]

30. Collier RJ, Dahl GE, VanBaale MJ. Major advances associated with environmental effects on dairy cattle. J Dairy Sci 2006; 89: 1244-1253. [Medline]

31. Zeron Y, Ocheretny A, Kedar O, Borochov A, Sklan D, Arav A. Seasonal changes in bovine fertility: relation to developmental competence of oocytes, membrane properties and fatty acid composition of follicles. Reproduction 2001; 121: 447-454. [Medline]

32. Andreu-Vázquez C, López-Gatius F, García-Ispierto I, Maya-Soriano MJ, Hunter RHF, López-Béjar M. Does heat stress provoke the loss of a continuous layer of cortical granules beneath the plasma membrane during oocyte maturation? Zygote 2010; 18: 293-299. [Medline]

33. Cavalieri J, Farin PW, Kinder JE, Van Camp SD, Whitacre MD, Washburn SP, Britt JH. Ovarian follicular development following administration of progesterone or aspiration of ovarian follicles in Holstein cows. Theriogenology 2001; 55: 805-821. [Medline]

34. Savio JD, Thatcher WW, Morris GR, Entwistle K, Drost M, Mattiacci MR. Effects of induction of low plasma progesterone concentrations with a progesterone-releasing intravaginal device on follicular turnover and fertility in cattle. J Reprod Fertil 1993; 98 77-84. [Medline]

35. Kinder JE, Kojima FN, Bergfeld EGM, Wehrman ME, Peters KE. Progestin and estrogen regulation of pulsatile $\mathrm{LH}$ release and development of persistent ovarian follicles in cattle. J Anim Sci 1996; 74: 1424-1440. [Medline]

36. Roche JF. Effect of short-term progesterone treatment on oestrous response and fertility in heifers. J Reprod Fertil 1974; 40: 433-440. [Medline]

37. Roche JF. Synchronization of oestrus in heifers with implants of progesterone. $J$ Reprod Fertil 1974; 41: 337-344. [Medline]

38. Roche JF. Control of oestrus in cattle using progesterone coils. Anim Reprod Sci 1978; 1 $145-154$

39. Brink JT, Kiracofe GH. Effect of estrous cycle stage at Synchro-Mate-B treatment on conception and time to estrus in cattle. Theriogenology 1988; 29: 513-518. [Medline]

40. Mihm M, Baguisi A, Boland MP, Roche JF. Association between the duration of dominance of the ovulatory follicle and pregnancy rate in beef heifers. $J$ Reprod Fertil 1994; 102: 123-130. [Medline]

41. Stock AE, Fortune JE. Ovarian follicular dominance in cattle: relationship between prolonged growth of the ovulatory follicle and endocrine parameters. Endocrinology 1993; 132: 1108-1114. [Medline]

42. Sirois J, Fortune JE. Ovarian follicular dynamics during the estrous cycle monitored by real-time ultrasonography. Biol Reprod 1988; 39: 308-317. [Medline]

43. Lopez-Gatius F, Szenci O, Bech-Sàbat G, García-Ispierto I, Serrano B, Santolaria P, Yániz J. Factors of non-infectious nature affecting late embryonic and early foetal loss in high producing dairy herds in north-eastern Spain. Magyar Allatorvosok Lapja 2009; 131: 515-531.

44. Lopez-Gatius F, García-Ispierto I. Ultrasound and endocrine findings that help to assess the risk of late embryo/early foetal loss by non-infectious cause in dairy cattle. Reprod Domest Anim 2010; 45(Suppl 3): 15-24.

45. Echternkamp SE, Gregory KE. Effects of twinning on gestation length, retained placenta, and dystocia. J Anim Sci 1999; 77: 39-47. [Medline]

46. Bicalho RC, Cheong SH, Galvao KN, Warnick LD, Guard CL. Effect of twin birth calvings on milk production, reproductive performance, and survival of lactating cows. $J$ Am Vet Med Assoc 2007; 231: 1390-1397. [Medline]

47. Andreu-Vázquez C, Garcia-Ispierto I, Ganau S, Fricke PM, López-Gatius F. Effects of twinning on the subsequent reproductive performance and productive lifespan of highproducing dairy cows. Theriogenology 2012; 78: 2061-2070. [Medline]

48. Garcia-Ispierto I, López-Gatius F. A three-day PGF2 $\alpha$ plus eCG-based fixed-time AI protocol improves fertility over spontaneous estrus in dairy cows with silent ovulation. $J$ Reprod Dev 2013; 59: 393-397. [Medline] 